\title{
Simulation Study of Nonlinear PI-Controller with Quasi-Z-Source Derived Push-Pull Converter
}

\author{
Andrii Chub (PhD Student, Tallinn University of Technology), \\ Oleksandr Husev (Senior Research Fellow, Tallinn University of Technology), \\ Dmitri Vinnikov (Principal Research Fellow, Tallinn University of Technology)
}

\begin{abstract}
This paper is focused on the control issues of the quasi-Z-source derived push-pull converter with integrated magnetic elements. The proposed converter is intended for applications that require a high gain of the input voltage and galvanic isolation, i.e. power conditioning systems for renewable energy sources, such as variable speed wind turbines with direct driven permanent magnet synchronous generators. Magnitude and frequency of the output voltage of such turbines are variable due to intermittent nature of the wind power. Despite number of advantages converter has complicated dynamic behavior. Simulations showed change of stability margin depending on current operation point of the wind turbine and output load. Closed loop control system should provide fast response and stable operation in the wide range of wind speeds. Simulations showed that the conventional PI-controller with saturation cannot satisfy those requirements. Nonlinear PI-controller was derived by adding adjustment block to the conventional PI-controller. Adjustment block is drastically changing proportional and integral gains of the controller according to sign of the output voltage error. Proposed controller is compared with conventional one by means of simulation in PSIM. Simulation results prove that proposed nonlinear control system has improved regulator performance.
\end{abstract}

Keywords - DC-DC power converters, automatic voltage control, closed loop systems, control system synthesis.

\section{INTRODUCTION}

Quasi-Z-source inverters (qZSI) were proposed in 2008 [1]. QZSI provides wide regulation freedom, continuous input current and high EMI immunity. These advantages make qZSI suitable for renewable power applications (solar panels, fuel cells, wind power generators, etc.) [2]-[5] and electric drive vehicle applications [6]. DC/DC converters derived from qZSI show high performance as an intermediate voltage matching converter between renewable energy source and grid-tied inverter [7]-[9].

Nowadays the permanent magnet synchronous generators (PMSG) are widely used in wind power applications [10], [11]. They are well known for high efficiency, low volume and relatively small weight. Multipole construction of PMSG allows its direct coupling to the blades. Elimination of gearbox improves volume and reliability of wind energy conversion system. PMSG-based small wind turbines can be used in residential power systems instead of diesel generators [12]. Quasi-Z-source DC/DC converters with galvanic high frequency isolation are suitable solution for three-stage grid integration system for PMSG-based wind turbines, which is shown in Fig. 1 [8]. In this configuration some energy storage

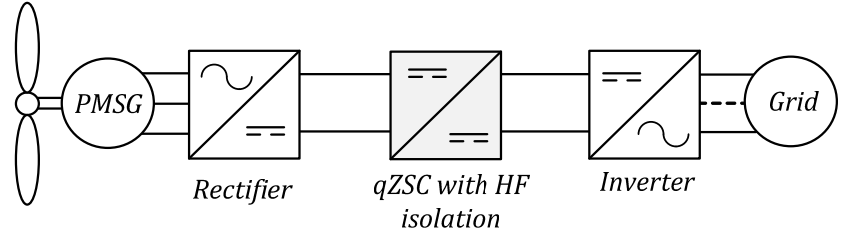

Fig. 1. Block diagram of PMSG-based wind turbine grid-integration system with intermediate qZSC with high-frequency isolation.

system can be easily integrated into DC-link between intermediate converter and grid-tied inverter.

Recent results in the analysis of the dynamic behavior of quasi-Z-source converter (qZSC) family revealed high complexity in estimation of their stability margins [13]. Smallsignal stability of qZSC depends on values of elements, duty cycle of shoot-through state and properties of the load [14]. Also, oscillations are possible as a result of input voltage disturbances [6]. These circumstances impose restrictions on controller design. Input voltage from renewable energy sources depends on instantaneous weather conditions and load. It follows therefore that the design of closed-loop control systems for renewable qZSC-based applications requires comprehensive analysis of stability and special types of controllers, for example, PI-compensator with feed forward control loop [14].

This paper is devoted to the control issues of the qZS-derived push-pull converter (qZSPPC). The converter was specially developed for the high frequency (HF) isolated intermediate stage of the interface converter for PMSG-based wind turbines. This step-up converter is able to operate in wide range of input voltages and provide continuous input current.

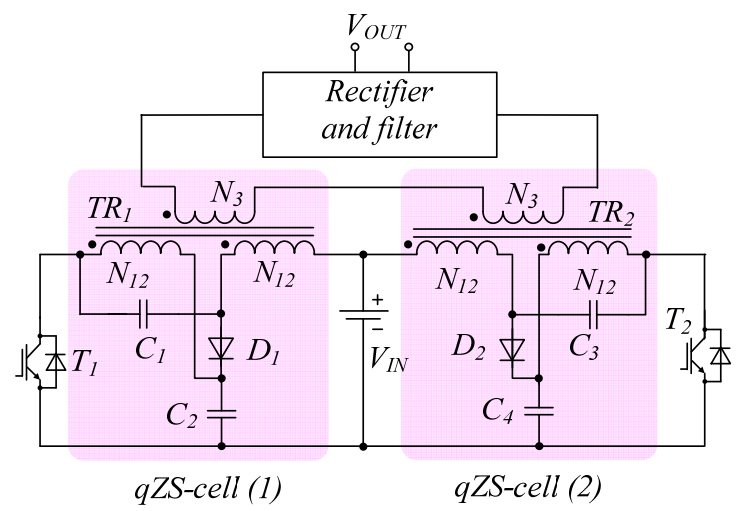

Fig. 2. Quasi-Z-source-derived push-pull converter (qZSPPC). 


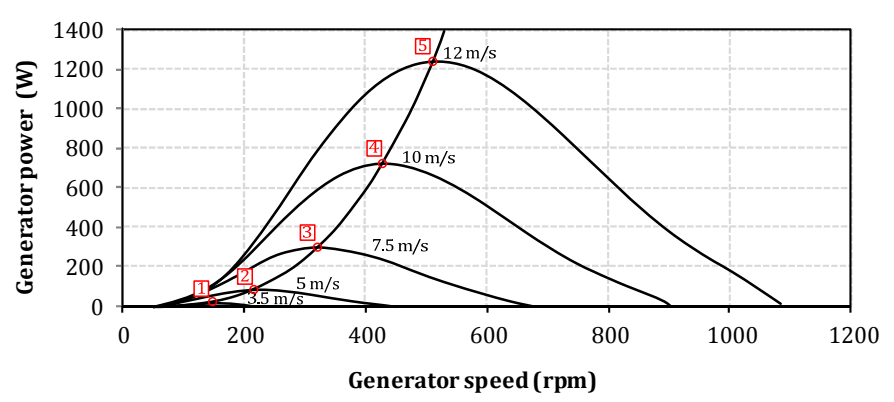

Fig. 3. PMSG-based WT power curves at various wind speeds.

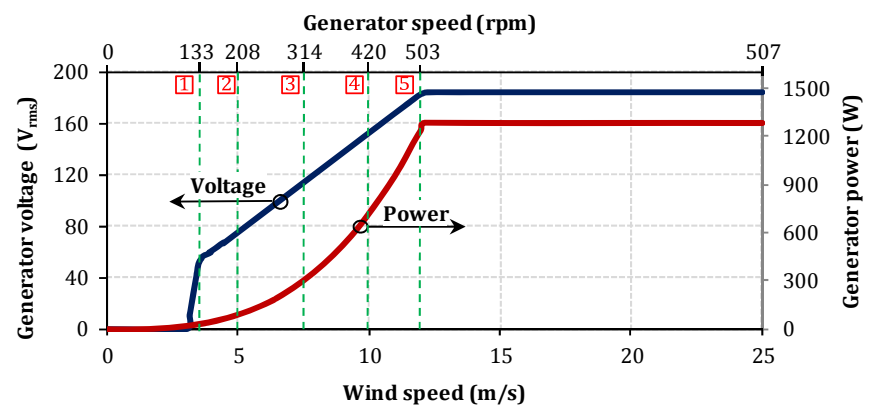

Fig. 4. PMSG-based WT power and voltage curves with MPPT.

\section{II.DESCRIPTION OF THE STUDIED SYSTEM}

Novel topology shown in Fig. 2 was firstly proposed in [15]. It was derived from the one-switch non-isolated qZSC by using coupled inductors. Two arms are working interleaved. Output windings are connected in series. Magnetizing inductances of three-winding transformers serve as energy storage elements in corresponding arms. Detailed steady-state analysis of this topology can be found in [15]. Each transistor is switched with the duty cycle $D_{A}<0.5$. qZSPPC was reported as suitable solution for PMSG-based wind turbines [16]. Static voltage gain of this converter in continuous conduction mode (CCM) is:

$$
G=\frac{V_{\text {OUT }}}{V_{I N}}=\frac{N_{3}}{N_{12}} \cdot \frac{2 \cdot D_{A}}{1-2 \cdot D_{A}} .
$$

Parameters of case study wind turbine were described in [16]. This data will be also used for simulations in the given paper. Both frequency and magnitude of the output voltage of PMSG-based wind turbine (WT) depend on the wind speed. Each value of wind speed corresponds to some rotation speed of the PMSG with maximum output power. It means that this type of WTs requires MPPT algorithm. Power curves for turbine are shown in Fig. 3. Red dots with indexes from 1 to 5 indicate maximum power operating points. This WT has cut-in speed $3.5 \mathrm{~m} / \mathrm{s}$. WT is operating with maximum output power at wind speeds between $12 \mathrm{~m} / \mathrm{s}$ and $25 \mathrm{~m} / \mathrm{s}$. It must be stopped at the wind speeds above $25 \mathrm{~m} / \mathrm{s}$ to avoid damage of WT [17].

Power and voltage curves in maximum power points for WT mentioned above are shown in Fig. 4 as functions of wind speed. Table I indicates values for open-loop operation of the qZSPPC for operating points $1 . . .5$ marked on Fig. 4. Load resistance, gain and duty cycle are calculated according to the next assumptions: CCM operation, $V_{\text {OUT }}=400 \mathrm{~V}, N_{12}=N_{3}$.

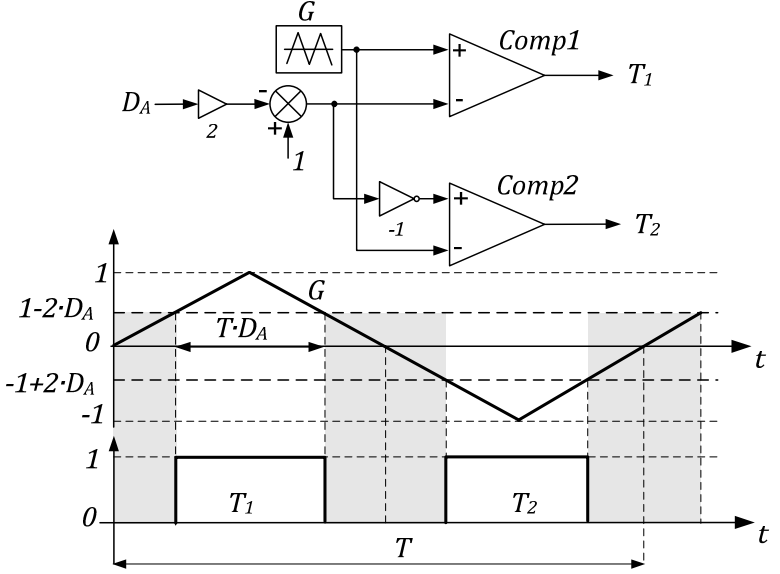

Fig. 5. Switching controller.

Converter is working in discontinuous conduction mode (DCM) in point 2 and close to the boundary between DCM and CCM modes in point 3. Operating point 5 corresponds to high wind speed when generator starts synchronous operation and CCM operation of the converter with highest input power.

From this it can be seen that the converter with closed-loop control system should be able to operate in complex behavior. The main challenges for control system:

- output power depends on load, but it is limited by weather conditions;

- control system should keep stable operation in wide range of frequencies of input voltage ripple from WT in variable speed - variable voltage operation mode;

- controller in combination with MPPT algorithm should provide sufficient stability and dynamic characteristics of transition processes in wide range of possible wind speed fluctuations [18].

\section{Numerical Simulation of CONVERTER DyNAmicS}

\section{A. Open-Loop Operation}

Converter model was built using PSIM software environment according to schematics in Fig. 2. Transformers have $1 \mathrm{mH}$ magnetizing inductance and the values of qZS capacitors $C_{1} \ldots C_{4}$ are equal to $15 \mathrm{uF}$. Full wave rectifier is used at the output in combination with passive LC-filter: $500 \mathrm{uH}$ and $12.5 \mathrm{uF}$. The scheme of simple switching controller is shown in Fig. 5.

In this subsection WT and rectifier are substituted with DC-voltage source. Modeling of the start-up processes for operating points $2 \ldots 5$ was made to estimate converter

TABLE I

SELECTEd OPERATING POINTS OF THE QZSPPC

\begin{tabular}{|c|c|c|c|c|c|}
\hline $\begin{array}{c}\text { Operating } \\
\text { point }\end{array}$ & $\begin{array}{c}\mathbf{V}_{\text {IN }} \\
\text { V(DC) }\end{array}$ & Gain & $\begin{array}{c}\mathbf{D}_{\text {A }} \\
\text { (simulated) }\end{array}$ & $\begin{array}{c}\text { Power, } \\
\mathbf{W}\end{array}$ & $\begin{array}{c}\text { Load, } \\
\text { Ohm }\end{array}$ \\
\hline 1 & 65 & 6.15 & 0.168 & 19 & 8421 \\
\hline 2 & 107 & 3.74 & 0.318 & 84 & 1905 \\
\hline 3 & 159 & 2.50 & 0.330 & 302 & 530 \\
\hline 4 & 216 & 1.85 & 0.307 & 717 & 223 \\
\hline 5 & 259 & 1.54 & 0.295 & 1276 & 125.4 \\
\hline
\end{tabular}




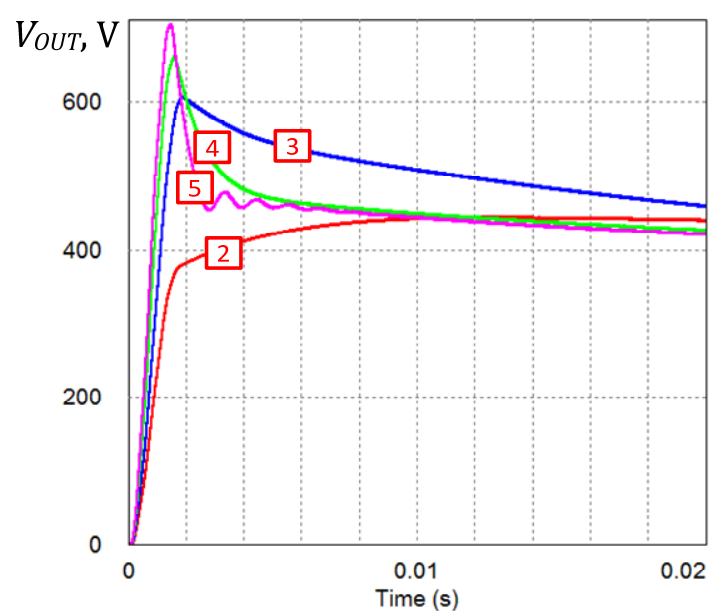

Fig. 6. Simulation results of start-up processes for operating points $2 \ldots 5$.

dynamics in five predefined operating points. Table I contains calculated values for modeling and measured simulated active duty cycle. From point 2 to point 5 input power of converter varies up to 15 times. As shown in Fig. 6 the overshoots appear in the output voltage during the starting of the WT. The higher is the input power the greater is the overshoot magnitude and shorter settling time. Operation with inrush voltage overshoot requires using overrated power semiconductors. This is additional challenge for control system to suppress overshoots and ensure satisfactory dynamics. Such behavior can be explained by the transition between DCM and CCM. QZSPPC can operate in one CCM mode and three DCM modes [19]. This means that the dynamics of the converter changes considerably in wide range of wind speeds.

\section{B. Closed-Loop Control System with PI Controller}

As far as there is no comprehensive small signal model of the investigated converter, closed-loop system based on PIcontroller can be adjusted manually by using numerical simulators. But it is possible that ideal numerical model will not reveal all possible challenges. If closed-loop system with PI controller loses stability, converter can be damaged. Adaptive PI- or PID-controller can improve system stability but requires complicated analysis with disputable assumptions to determine control law.

Closed-loop system based on the PI-controller was implemented in PSIM to illustrate how stability margins can

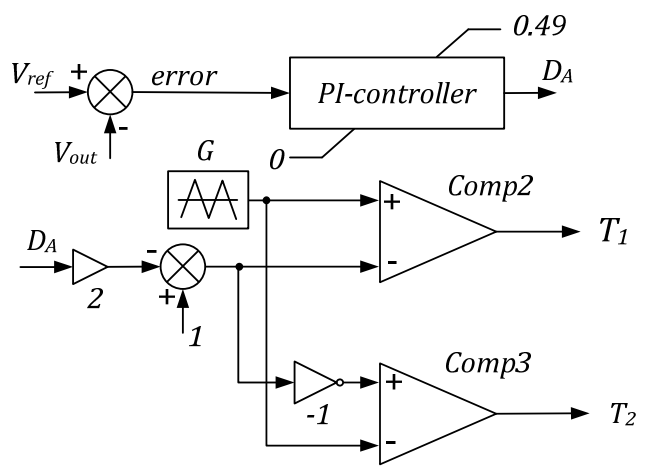

Fig. 7. Closed-loop control system with linear PI-controller.

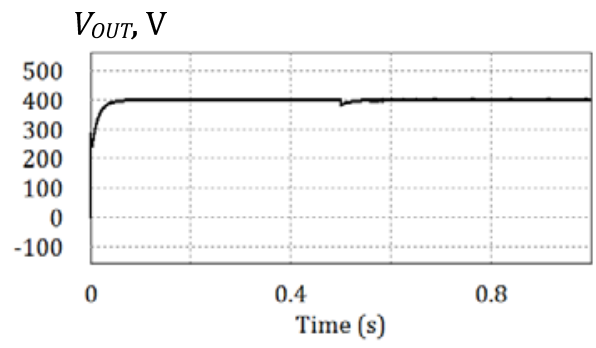

(a)

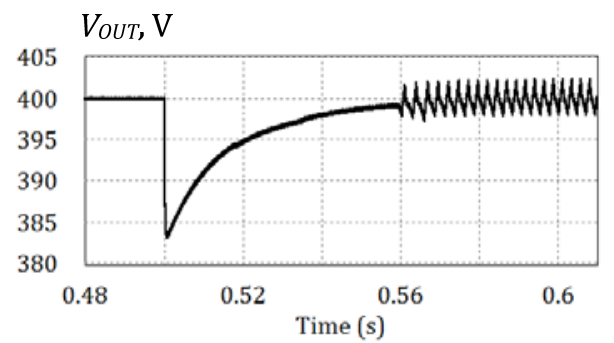

(b)

Fig. 8. Load step response of the closed-loop control system with linear PI-controller for operating point 4: (a) on a large scale and (b) detailed scale.

move dependently on the operation mode. PI-controller shown in Fig. 7 has transfer function: $\mathrm{PI}(\mathrm{s})=\mathrm{k} \cdot(1+\mathrm{sT}) /(\mathrm{sT})$. Also, anti-windup principle was implemented with additional limiter. It keeps output of PI-regulator (active duty cycle) in realistic range from 0 to 0.49 . Parameters of PI-controller were adjusted manually to the next values: $\mathrm{k}=0.001, \mathrm{~T}=0.01$. In the model implemented the converter has constant input voltage. This assumption removes one of the complexities of real system - variable frequency ripple of the output voltage of WT. It was made to analyze closed-loop dynamic of the converter separated from influence of the real input source.

Simulations were made to show how closed-loop system behaves when the output power increases from $50 \%$ to $100 \%$ out of maximum output power of WT in corresponding operating point. In points $1 \ldots 3$ and 5 system showed satisfactory response. Problems with stability occur in point 4 : $\mathrm{V}_{\mathrm{IN}}=216 \mathrm{~V}, \mathrm{P}_{\mathrm{OUT}}=302 \mathrm{~W}$. Fig. 8(a) shows start-up process with $50 \%$ load and load step to the $100 \%$ at $t=0.5 \mathrm{~s}$. Detailed load step response is shown in Fig. 8(b). After the load step the overall system stability has changed noticeably. Considerable rise of the output voltage ripple after $\mathrm{t}=0.56 \mathrm{~s}$ means that the dynamic behavior of a system has changed after the load step. Detailed estimation of stable operating region is impossible with numerical simulation.

\section{Modeling of the WT}

In previous simulations PMSG-based WT and input rectifier were substituted with the constant voltage source. Real WT generates variable frequency voltage and has internal parasitic inductances in phases. Case study WT has 8 poles, phase resistance $1.2 \mathrm{Ohm}$ and internal phase inductance $5 \mathrm{mH}$. WT generates sinusoidal voltage with line-to-line RMS value $46 \mathrm{~V} \ldots 183 \mathrm{~V}$ and frequency $16.6 \mathrm{~Hz} . .63 .4 \mathrm{~Hz}$. In further simulations WT and rectifier are substituted with three-phase sinusoidal voltage source $e_{g 1} \ldots e_{g 3}$, three resistors $R_{g 1} \ldots R_{g 3}$, three inductors $L_{g 1} \ldots L_{g 3}$ and uncontrolled three-phase diode rectifier $D_{1} \ldots D_{6}$ as shown in Fig. 9. Uncontrolled rectifier 


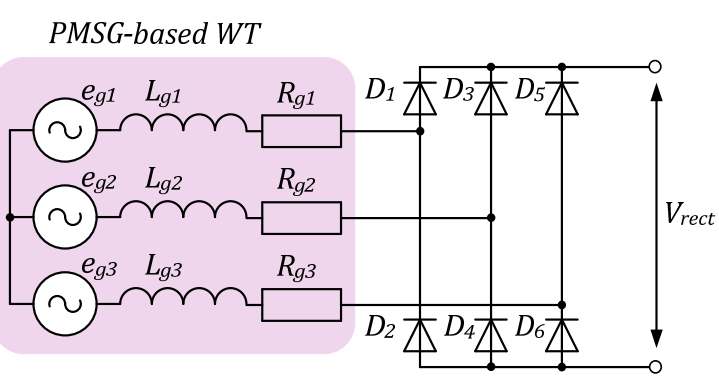

Fig. 9. Used equivalent circuit for WT with three-phase rectifier.

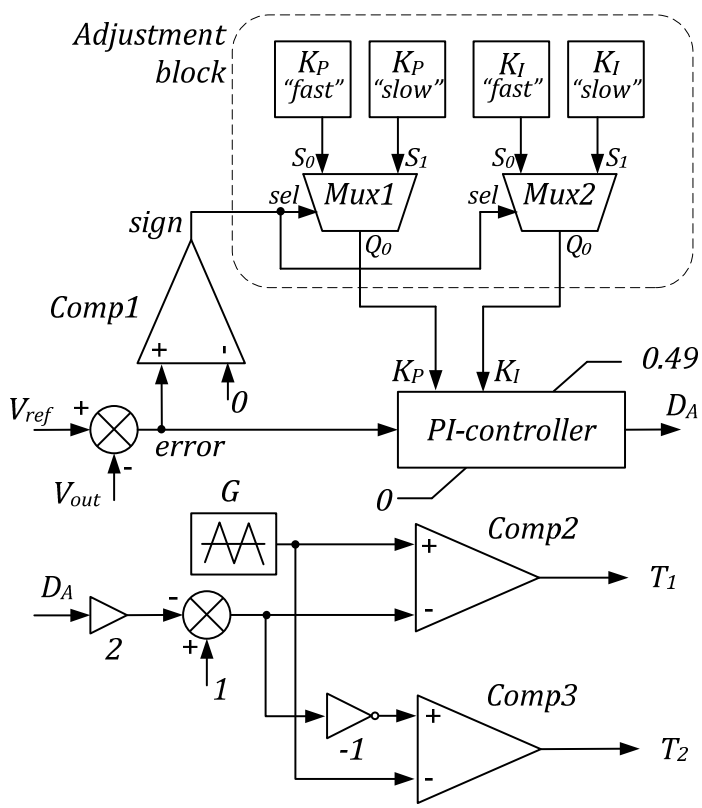

Fig. 10. Structure of the proposed controller. possesses merits such as reduced component count and low price. Additionally, it does not allow torque and speed control at first stage of grid integration system and has poor energy utilization at low speeds [20], [21].

It was practically impossible to tune analytically linear PI-controller with used equivalent circuit for WT. Conventional open-loop tuning methods, such as Ziegler-Nichols and Cohen-Coon methods, cannot be used due to AC component in the input voltage. In this case the design of controller requires comprehensive stability analysis also for the large signal.

\section{Proposed Control System}

Fig. 10 shows the proposed nonlinear controller. The main difference with linear PI-controller is adjusting block. It changes gains of the proportional and integral components of PI-controller according to the sign of error signal. Transfer function of used PI-controller: $\mathrm{PI}(\mathrm{s})=\left(K_{I}+K_{P} \cdot \mathrm{s}\right) /(\mathrm{s})$. Positive error corresponds to the relatively slow response of the controller. In case of negative error PI-controller gets higher integral $\left(K_{I}\right)$ and proportional $\left(K_{P}\right)$ gains. Comparator Comp1 detects sign of the error signal. Adjustment block contains two multiplexers Mux1 and Mux2. Error sign defines which of two inputs is connected to the output in each multiplexer. Mux1 provides gain for the proportional component $\left(K_{P}\right)$ of the PI-controller. Mux2 in its turn provides gain for the integral component $\left(K_{I}\right)$ of the PI-controller. Also driven PI-controller utilizes anti-windup technique to improve stability.

Change of the wind speed is relatively slow comparing to the converter switching frequency. In residential applications start-up and load step processes are the most challenging for
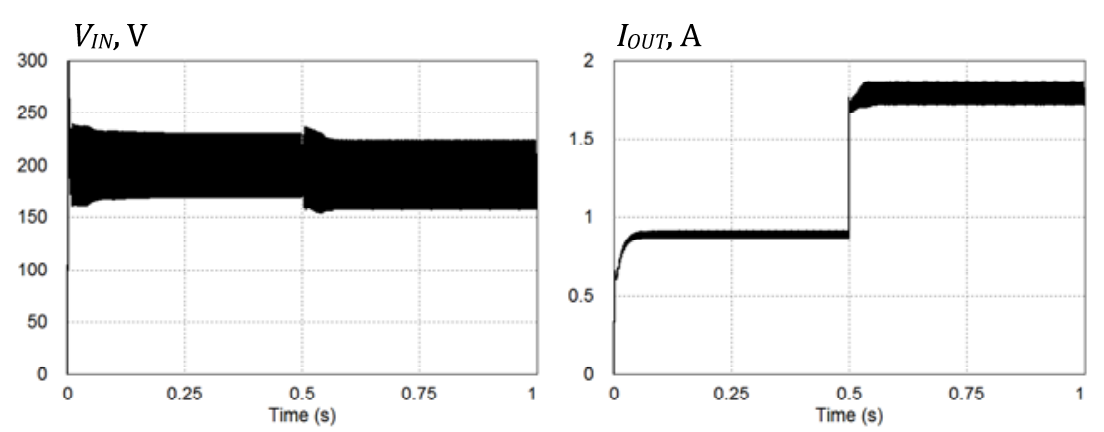

(a)
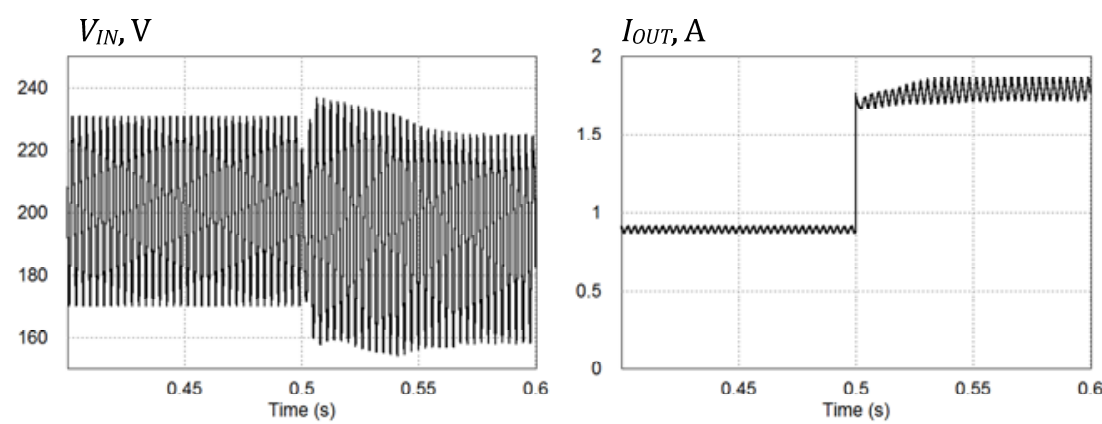

(b)
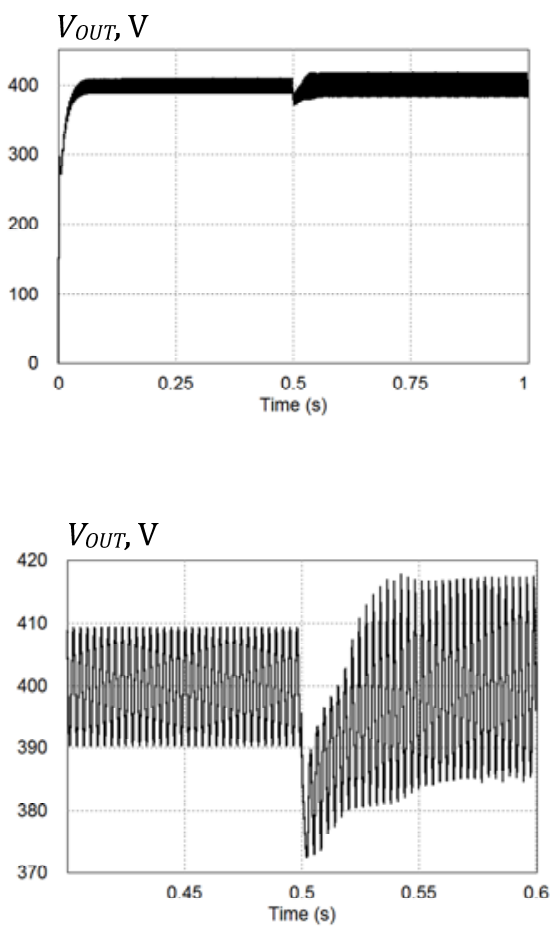

Fig. 11. Start-up and load step transient of the converter with PI-controller: (a) large and (b) detailed scale. 

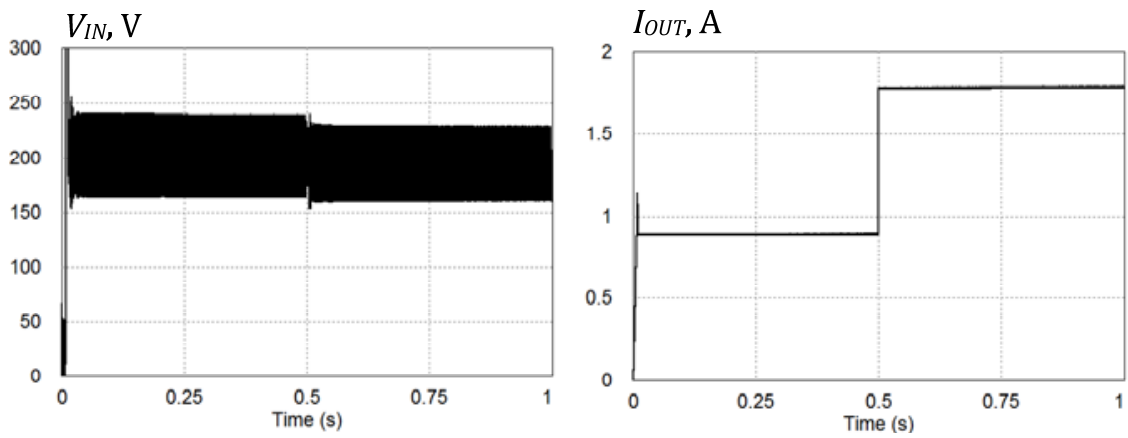

(a)
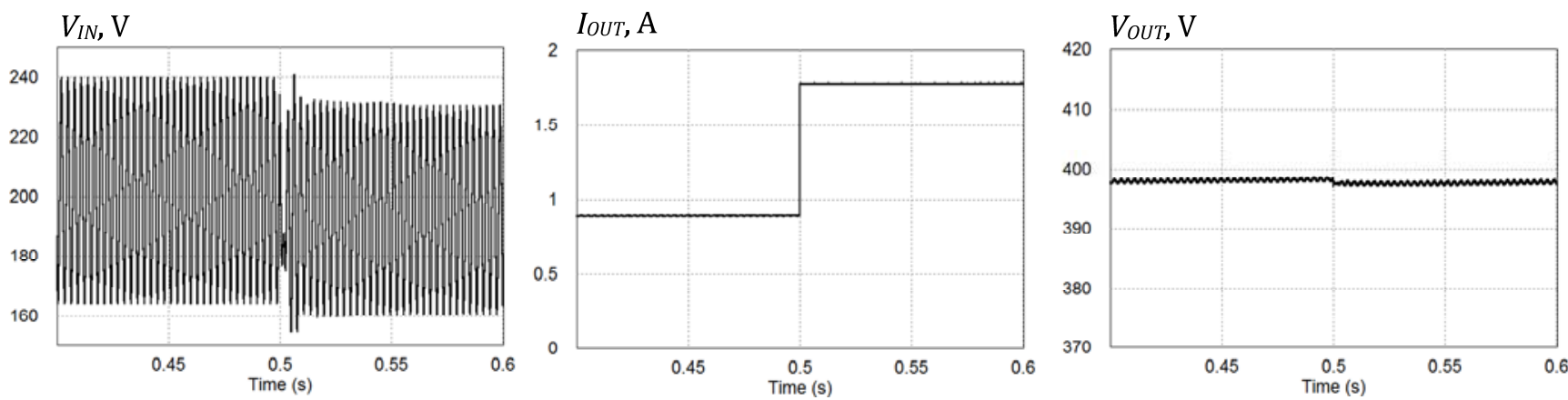

(b)

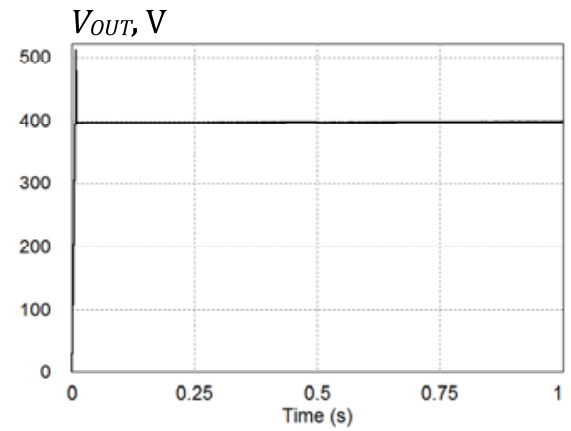

$$
\text { . }
$$




\section{REFERENCES}

[1] J. Anderson, F. Z. Peng, "Four Quasi-Z-Source Inverters," in Proceedings of Power Electronics Specialists Conference 2008 (PESC’2008), pp. 2743-2749, 15-19 June 2008.

[2] C. Roncero-Clemente, S. Stepenko, O. Husev, V. Miñambres-Marcos, E. Romero-Cadaval, and D. Vinnikov, "Three-Level Neutral-PointClamped Quasi-Z-Source Inverter with Maximum Power Point Tracking for Photovoltaic Systems," Technological Innovation for the Internet of Things, vol. 394, L. Camarinha-Matos, S. Tomic, and P. Graça, Eds., ed: Springer Berlin Heidelberg, 2013, pp. 334-342.

[3] Yuan Li, J. Anderson, F.Z. Peng, Dichen Liu, "Quasi-Z-Source Inverter for Photovoltaic Power Generation Systems," in Proceedings of TwentyFourth Annual IEEE Applied Power Electronics Conference and Exposition, (APEC’2009), pp. 918-924, 15-19 Feb. 2009.

[4] Liu Yushan, Baoming Ge, Fang Zheng Peng, Abu Rub Haitham, Anibal T. de Almeida, Fernando J.T.E. Ferreira, "Quasi-Z-Source Inverte Based PMSG Wind Power Generation System," in Proceedings of 2011 IEEE Energy Conversion Congress and Exposition (ECCE’2011), pp. 291-297, 17-22 Sept. 2011.

[5] C. Roncero-Clemente, E. Romero-Cadaval, O. Husev, D. Vinnikov, and S. Stepenko, "Simulation of Grid Connected Three-Level Neutral-PointClamped qZS Inverter using PSCAD,” The Scientific Journal of Riga Technical University - Electrical, Control and Communication Engineering, vol. 2, pp. 14-19.

[6] Feng Guo, Lixing Fu, Chien-Hui Lin, Cong Li, Woongchul Choi, Jin Wang, "Development of an 85-kW Bidirectional Quasi-Z-Source Inverter With DC-Link Feed-Forward Compensation for Electric Vehicle Applications," IEEE Transactions on Power Electronics, vol. 28, no. 12, pp. 5477-5488, Dec. 2013.

[7] D. Vinnikov, I. Roasto, "Quasi-Z-Source-Based Isolated DC/DC Converters for Distributed Power Generation," IEEE Transactions on Industrial Electronics, vol. 58, no. 1, pp. 192-201, Jan. 2011.

[8] D. Vinnikov, L. Bisenieks, I. Galkin, "New Isolated Interface Converter for PMSG based Variable Speed Wind Turbines," Przeglad Elektrotechniczny, vol. 88, no 1a, pp. 75-80, 2012.

[9] D. Vinnikov, I. Roasto, R. Strzelecki, M. Adamowicz, "Step-Up DC/DC Converters With Cascaded Quasi-Z-Source Network," IEEE Transactions on Industrial Electronics, vol. 59, no. 10, pp. 3727-3736, Oct. 2012.

[10] M. Arifujjaman, M.T. Iqbal, J.E. Quaicoe, "A comparative study of the reliability of the power electronics in grid connected small wind turbine systems," in Proceedings of Canadian Conference on Electrical and Computer Engineering 2009 (CCECE’09), pp. 394-397, 3-6 May 2009.

[11] F. Blaabjerg, M. Liserre, K. Ma, "Power Electronics Converters for Wind Turbine Systems," 2011 IEEE Energy Conversion Congress and Exposition (ECCE’2011), pp. 281-290, 17-22 Sept. 2011.

[12] L. Barote, C. Marinescu, "PMSG Wind Turbine System for Residential Applications," in Proceedings of 2010 International Symposium on Power Electronics Electrical Drives Automation and Motion (SPEEDAM'2010), pp. 772-777, 14-16 June 2010.

[13] O. Husev, D. Vinnikov, I. Roasto, "Stability Analysis of the Quasi-ZSource DC/DC Converter Based on Small Signal Model," in Proceedings of 2012 International Symposium on Power Electronics, Electrical Drives, Automation and Motion (SPEEDAM'2012), pp. 298303, 20-22 June 2012.

[14] Yuan Li, Fang Z. Peng, "AC Small Signal Modeling, Analysis and Control of Quasi-Z-Source Converter," in Proceedings of 7th International Power Electronics and Motion Control Conference (IPEMC'2012), vol. 3, pp. 1848-1854, 2-5 June 2012.

[15] D. Vinnikov, J. Zakis, O. Husev, R. Strzelecki, "New High-Gain Step-Up DC/DC Converter with High-Frequency Isolation," 2012 Twenty-Seventh Annual IEEE Applied Power Electronics Conference and Exposition (APEC’2012), pp. 1204-1209, 5-9 Feb. 2012.

[16] A. Blinov, D. Vinnikov, O. Husev, A. Chub, "Experimental Analysis of Wide Input Voltage Range qZS-derived Push-Pull DC/DC Converter for PMSG-based Wind Turbines," in Proceedings of PCIM Europe 2013 Nuremberg, Germany, 14-16 May 2013. Berlin: VDE VERLAG GMBH, 2013, pp. 1435-1444.

[17] Manfred Stiebler, Wind Energy Systems for Electric Power Generation. Berlin: Springer Verlag Berlin Heidelberg, 2008.

[18] He Xu; Jing Hui; Dinghui Wu; Wenxu Yan, "Implementation of MPPT for PMSG-based small-scale wind turbine," in Proceedings of 4th IEEE Conference on Industrial Electronics and Applications (ICIEA'2009), pp. 1291-1295, 25-27 May 2009
[19] O. Husev, A. Blinov, D. Vinnikov, A. Chub, "Steady-State Analysis of qZS-Derived Push-Pull DC/DC Converter with Wide Input Voltage Regulation Range," in Proceedings of 8th International ConferenceWorkshop Compatibility and Power Electronics (CPE'2013), pp. 320-325, Ljubljana, Slovenia, 05-07 June 2013.

[20] M. Pathmanathan, C. Tang, W.L. Soong, N. Ertugrul, "Comparison of Power Converters for Small-Scale Wind Turbine Operation," in Proceedings of 2008 Australasian Universities Power Engineering Conference (AUPEC’08), pp. 1-6, 14-17 Dec. 2008.

[21] Shao Zhang, King-Jet Tseng, D.M. Vilathgamuwa, Trong Duy Nguyen, Xiao-Yu Wang, "Design of a Robust Grid Interface System for PMSGBased Wind Turbine Generators," IEEE Transactions on Industrial Electronics, vol. 58, no. 1, pp. 316-328, Jan. 2011.

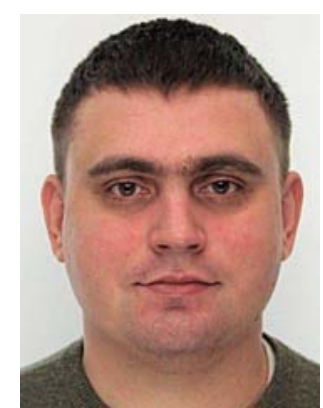

Andrii Chub received the B.Sc. degree in Electronics and M.Sc. degree in Electronic Systems from Chernihiv State Technological University, Chernihiv, Ukraine, in 2008 and 2009 respectively.

He is currently pursuing the Ph.D. degree in the Power Electronics Research Group at the Department of Electrical Engineering, Tallinn University of Technology. He is currently an Engineer at the Department of Electrical Engineering, Tallinn University of Technology. His research interests include dc-dc converters, dc-ac inverters, implementation of the new wide bandgap semiconductors in power converters, and control of the renewable energy conversion systems.

Postal address: Department of Electrical Engineering, Tallinn University of Technology, Ehitajate tee 5, 19086 Tallinn, Estonia, e-mail: andrii.chub@ieee.org

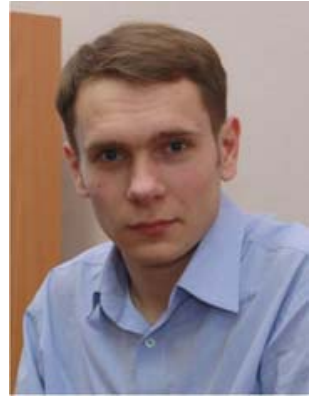

Oleksandr Husev received the B.Sc. and M.Sc. degrees in industrial electronics from Chernihiv State Technological University, Chernihiv, Ukraine, in 2007 and 2008 respectively. He defended $\mathrm{PhD}$ thesis in the Institute of Electrodynamics of the National Academy of Science of Ukraine in 2012.

He is senior researcher of the Department of Electrical Engineering, Tallinn University of Technology and assistant of the Department of Biomedical Radioelectronics Apparatus and Systems, Chernihiv State Technological University. He has over 40 publications and is

the holder of several patents.

His research interests are in control systems for power electronic converters based on a wide range of algorithms, including modeling, design, and simulation, applied design of power converters and control systems and application.

Postal address: Department of Electrical Engineering, Tallinn University of Technology, Ehitajate tee 5, 19086 Tallinn, Estonia, e-mail: gsfki@ukr.net

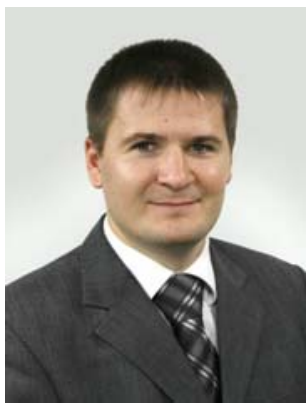

Dmitri Vinnikov received the Dipl.Eng., M.Sc., and Dr.Sc.techn. degrees in electrical engineering from Tallinn University of Technology, Tallinn, Estonia, in 1999, 2001, and 2005, respectively.

He is currently a Head of the Power Electronics Research Group at the Department of Electrical Engineering, Tallinn University of Technology. He has authored more than 100 published papers on power converter design and development and is the holder of several patents and utility models in this application field. His research interests include switchmode power converters, modeling and simulation of power systems, applied design of power converters and control systems, and application and development of energy storage systems.

Postal address: Department of Electrical Engineering, Tallinn University of Technology, Ehitajate tee 5, 19086 Tallinn, Estonia, e-mail: dmitri.vinnikov@ieee.org 